\title{
СТАНОВЛЕНИЕ ХОККЕЯ С МЯЧОМ, КАК КУЛЬТУРНОГО ЯВЛЕНИЯ, В ПЕРВОЙ ПОЛОВИНЕ ХХ ВЕКА
}

\section{FORMATION OF BANDY AS A CULTURAL PHENOMENON IN THE FIRST HALF OF THE XX CENTURY}

\section{T. Krasilnikov}

Summary: The article examines the development of bandy in Russia in the first half of the XX century. It is traced how in the Soviet era, bandy gradually turned from «bourgeois fun» into a national sport, the uniqueness of which was also emphasized by the original hockey rules, which led to the emergence of the sports concept of «Russian hockey». The influence of the Soviet state on the development of hockey as a mass sport is noted.

Keywords: bandy, mass sports, history of sports in the USSR, «production principle» in Soviet sports.
$\Phi$ изическая культура и спорт в их современном понимании возникли в первой половине XIX века. Но подлинный расцвет происходит уже в XX веке, когда из модного увлечения буржуазной молодежи городского общества в начале века физическая культура и спорт превращаются к концу века в явления общественной и культурной жизни, становится предметом особого государственного регулирования и политического влияния. B начале XXI века общепризнанным является тот факт, что спорт играет социально значимую роль в жизни общества и государства.

В начале XX века, когда в России зарождался современный спорт, основным временем досуга являлись театр и кинематограф. Однако в отличие от театра, который в целом носил элитарный характер, и кино посещение спортивных мероприятий было более дешевым, что привлекало значительную массу публики [21]. Более того, в спортивных мероприятиях в отличие от театральных постановок или кинофильмов присутствует элемент неожиданности, поскольку невозможно воспроизвести «сценарий» какого-либо спортивного состязания даже с участием тех же спортсменов или спортивных команд. Неожиданность в большей мере способствует переживанию болельщика за действиями спортсменов.

K началу XX века собственно на открытом воздухе зимой соревновались в беге на лыжах и коньках, к середине века как вид спорта оформился санный спорт. Из всех командных видов спорта на открытом воздухе зимой играли только в хоккей.

\author{
Красильников Тимофей Сергеевич \\ аспирант, Московский городской педагогический \\ университет, Москва \\ krass000@mail.ru
}

Аннотация: В статье рассматривается развитие хоккея с мячом в России в первой половине XX века. Прослеживается, как в советскую эпоху хоккей с мячом постепенно превратился из «буржуазной забавы» в национальный вид спорта, уникальность которого подчеркивалась также своеобразными хоккейными правилами, что привело к возникновению спортивного понятия «русский хоккей». Отмечается влияние советского государства на развитие хоккея как вида массового спорта.

Ключевые слова: хоккей с мячом, массовый спорт, история спорта в СССР, «производственный принцип» в советском спорте.

Хоккей на льду как спортивная игра зародилась в Великобритании в первой половине XIX века. В качестве спортивного снаряда могли быть использованы как шайба (первоначально деревянная, затем - резиновая), так и мяч (деревянный в веревочной оплетке либо гуттаперчевый) [15, С.6 7], [19, С.36-45]. В конце XIX века в хоккей с мячом стали играть в России [16, С.8-9].

В тот момент — на рубеже XIX - XX веков - не было еще четкого разграничения между такими разновидностями игр на льду как хоккей с мячом и хоккей с шайбой. Разграничение между обоими видами спорта с ярко выраженной специализацией игроков начинает происходить в 20-х гг. XX века, когда в программу Олимпийский игр был включен хоккей с шайбой, и когда Международная федерация хоккея на льду для проведения соревнований принимает канадские правила игры в хоккей с шайбой [31, PP.59-61,76,96].

В отличие от хоккея с шайбой, где можно наблюдать как в течение 1920-х - 1930-х годов вырабатывались единые правила проведения международных соревнований, в хоккее с мячом в первой половине XX века не было создано не только международной спортивной организации, но даже международные товарищеские матчи носили эпизодический характер.

Во многом такая ситуация в хоккее с мячом сложилась вследствие различной трактовки правил игры.

Так, в начале 1920-х годов в Европе существовало 
несколько разновидностей игры в хоккей с мячом: вопервых, вариант игры в хоккей с мячом в формате «7 на 7» (эта разновидность хоккея с мячом исчезает с 1928 года) [17, С.28-30], во-вторых, вариант игры в хоккей с мячом в формате «11 на 11». Последний вариант игры в свою очередь был представлен в двух видах, которые сложились в 1910-ые годы и которые в спортивной печати впоследствии были названы «скандинавский bandy» и «русский хоккей». Отметим, что оба варианта хоккея с мячом в формате «11 на 11» игрались на площадке почти одинаковых размеров, близкие по размеру к футбольным. Но в «скандинавском bandy» разрешалось игра высоко летящим мячом, ворота были большими по размеру (2,10 метра в высоту на 3,50 метра в ширину), вратарь играл без клюшки, сами клюшки и мяч были более легкими по размеру. В «русском хоккее» игра высоко летящим мячом была запрещена, что повлекло за собой установление меньшего размера ворот (высота - 1,20 метра, ширина - 3,04 метра), запрещалось поднимать клюшку ото льда выше перекладины ворот, «желая этим избегнуть высоких ударов, причиняющих ушибы лиц». Также были введены бортики вдоль линии поля. Вратарь должен был выходить на поле с клюшкой [23, C.84-85].

Унификация правил «скандинавского bandy» и «русского хоккея» была произведена лишь в 1952-1953 годах. Унифицированные правила были опробованы на московских международных турнирах 1954 и 1955 годов, после чего можно говорить о рождении современного хоккея с мячом [23, С.85].

В течение длительного времени - в 1905 по 1952 годы - хоккей с мячом в России как спортивная игра представлял собой уникальное явление, поскольку развитие игры осуществлялось по собственным правилам, независимо от международных спортивных тенденций.

Благодаря высокой популярности среди болельщиков, можно утверждать, что к середине XX века хоккей с мячом становится национальным видом спорта.

В 1955 году вышел справочник «Хоккей в СССР», автором которого был спортивный журналист А.С. Перрель [23]. В справочнике автор изложил историю важнейших отечественных соревнований по хоккею первой половины XX века вплоть до унификации правил «русского хоккея» и «скандинавского bandy».

Справочник А.С. Перреля «Хоккей в СССР» заложил основные направления публикаций по истории хоккея с мячом, когда авторами выступали спортивные журналисты и спортивные статистики. В таких работах в первую очередь освещались спортивные результаты и, одновременно, давались краткие журналистские очерки о прошедших спортивных состязаниях. Несмотря на то, что указанные публикации нельзя назвать строго науч- ными, авторами была проделана значительная работа по поиску и обработке первоисточников, включая работу в архивах, обработку статистической информации, проведенных опросов и интервью непосредственных участников спортивных событий. Среди таких авторов следует выделить В.В. Фролова [22], В.И. Осипова [16], [17], А.В. Комарова [24], И.С. Добронравова [10], М.И. Щеглова [25], [26], В.И. Соснина [18], [25], И.А. Морозова [13], А.В. Куроша [12], В.Ф. Антуфьева [9].

В тоже время существует незначительное количество специальных научных исследований, посвященных проблематике хоккея с мячом. В первую очередь, следует назвать исследования, посвященные методикам тренировок спортсменов, которые были проведены в рамках педагогической науки. К таким исследованиям, в частности, относятся работы И.А. Каркавцевой [28], О.А. Фатеевой [29], В.А. Ходкевича [30], где лишь фрагментарно описываются отдельные события из истории «русского хоккея».

Совсем редкими являются исторические исследования по названной проблематике. Носят они региональный характер и хронологически изучают историю хоккея с мячом в нашей стране во второй половине XX века, что определяется более обширным комплексом имеющихся источников. Среди таких работ можно отметить работу А.Б. Анохиной «Развитие физической культуры и спорта в Ульяновской области в 1945 - 1991 гг.» [27], где автор уделил особое внимание истории команды по хоккею с мячом «Волга» (Ульяновск), как основному направлению развития спорта в Ульяновской области, и работу 0.3. Зиганшина «История развития хоккея с мячом» [11], в которой основное внимание уделено развитию этого вида спорта на Дальнем Востоке. В целом, можно утверждать, что хоккей с мячом все еще остается малоизученным культурным явлением отечественной истории. Особый интерес вызывает история этого вида спорта именно в первой половине XX века, когда и был сформирован хоккей с мячом, как культурное явление, как национальная спортивная командная игра.

Как уже было отмечено, в хоккей с мячом стали играть в России в конце XIX века. Если в первые годы XX века хоккейные команды появлялись только в Москве и Санкт-Петербурге, то в начале 1910-ых годов (до Первой мировой войны) в хоккей с мячом начинают играть не только в крупных городах европейской городах, но и на Дальнем Востоке [16, С.11]. В частности, во Владивостоке в 1915 году отмечено проведение турнира по хоккею с мячом для женских команд, который считается первым в истории отечественного хоккея с мячом [20, С.10].

Октябрьская революция 1917 года и провозглашенные ей принципы построения социалистического общества существенным образом отразились на многих 
аспектах общественной жизни, в том числе и на спорте. В 1922 году в РСФСР впервые в мировой практике был образован специализированный орган государственной власти - «спортивное министерство», ответственное за развитие физической культуры и спорта в стране. В структуре Всесоюзного Комитета по делам физической культуре и спорта при Совнаркоме СССР была создана секция хоккея и футбола [1], которая вплоть до 1958 года организовывала проведение общесоюзных соревнований по данным видам спорта.

В первые годы советской власти спорт рассматривался как один из факторов подготовки к труду и обороне, особое развитие получили легкая и тяжелая атлетики, стрельба, единоборства, гимнастика. Спортивные игры некоторое время не рассматривались в качестве основных и подлежащих развитию в стране, и только впоследствии было признано, что командные виды спорта развивают коллективизм, провозглашенный одним из принципов построения нового социалистического общества. В качестве командных и, что немаловажно, общедоступных и популярных видов спорта рассматривались: летом - футбол, зимой — хоккей с мячом.

При этом следует сказать что, благодаря футболу, который в начале XX века считался игрой менее «благородной», чем хоккей, в зимний вид спорта перешли принципы коллективной игры [10, Т.1, С.21]. В свою очередь, из-за универсализма многих спортсменов первой половины XX века хоккей с мячом не только использовался в тренировочном процессе футбольных команд, но привлекал на стадионы болельщиков, желавших видеть состязания любимых игроков не только летом, но и зимой.

В довоенной советской периодической спортивной печати - журналах «Спартак» (выходил в Ленинграде) и «Физкультура и спорт» (выходил в Москве), публиковались специальные статьи, посвященные хоккею с мячом. В этих статьях рассматривались не только принципы организации командных и индивидуальных тренировок по хоккею с мячом [4], технике нанесения ударов по мячу [2], но были также статьи о том, каким образом должна быть изготовлена клюшка для хоккея с мячом [3].

В 1923 году в практику советских спортивных организаций был введен «производственный принцип», когда спортивные клубы возникали при каком-либо предприятии или организации, которые должны обеспечивать материально-техническую базу своих спортивных клубов, включая введения в штат организаций должностей спортивных инструкторов [14, С.66-67]. Дополнительные средства для развития спорта в организации предоставляли профсоюзные организации, для которых в централизованном порядке было принято решение о необходимости обеспечить досуг рабочих и служащих в свободное от работы время. Расширение материальной базы спортивных клубов влекло все большее привлечение заинтересованных лиц к занятию спортом, появлению детских команд. С 1924 года в практику проведения городских соревнований - первоначально Москвы и Ленинграда, а затем по всей стране, вводится «клубный зачет», когда победитель определялся по итогам выступлений нескольких команд. Значимой с турнирной точки зрения являлась победа клубом, нежели отдельной команды. Можно отметить, что соревнования по «клубному зачету» являлись в некотором роде «визитной карточкой» советского массового спорта, что способствовало развитию массового не только взрослого, но также юношеского и детского спорта. Укрепление материально-технической базы спортивных клубов и введение «клубного зачета» привели к резкому увеличению числа хоккейных команд. К примеру, если в середине 1920-х годов в первенстве Москвы по хоккею с мячом «клубный зачет» проводился по итогам выступлений трех мужских команд одного клуба, то в начале 1940-х годов в рамках «клубного зачета» выступали уже 10 хоккейных команд одного клуба (пять мужских команд, команда юношей, команда мальчиков, две женские команды, команда девочек).

Увеличение числа хоккейных команд, расширение спортивного календаря способствовало повышению и зрительского интереса. Интересно отметить, что «производственный принцип» не только способствовал укреплению материально-технической базы спортивных клубов, но также повлек формирование особого поведения болельщиков, среди которых стало принято «болеть за своих», т.е. переживать за команду «своего завода», «своего профессионального общества».

К середине 1930-х годов в отечественном спорте наметилась тенденция проведения общесоюзных и республиканских соревнований с более широким привлечением спортсменов, ранее выступавших на городских соревнованиях. Особенно остро встала необходимость проведения национальных первенств среди отдельных клубов по футболу и хоккею, поскольку проводимые до 1934 - 1935 годов чемпионаты страны среди сборных команд городов уже не способствовали росту мастерства у спортсменов, не позволяли выявить молодых талантливых спортсменов.

«Пионерами» проведения соревнований среди клубов в СССР стали хоккеисты (хоккей с мячом). В марте 1935 года было проведено межведомственное первенство СССР, в котором участвовали еще пока сборные команды, но представлявшие уже не города, а спортивные общества «Динамо», «Спартак», ВЦСПС и РККА [5]. А уже через год - в феврале 1936 года - был проведен первый чемпионат СССР среди клубов добровольных спортивных обществ и ведомств по хоккею с мячом. Положительный опыт проведения обоих хоккейных турниров 
позволили в 1936 году организовать клубный чемпионат СССР по футболу [6], где существенно расширилась география команд-участниц.

Начиная с 1937 года и вплоть до 1954 года, главным соревнованием по хоккею с мячом становится розыгрыш Кубка СССР. Основное отличие кубкового турнира от первенства (чемпионата) является принцип в определении победителя матча. Первенство проводится по так называемой «круговой системе», когда каждый встречается с каждым. Эта формула проведения спортивного состязания обоснованно считается справедливой в отличие от кубкового турнира (в настоящее время понимаемый как «плей-офф»), где соревнования проводятся по принципу выбывания после первого поражения. Однако выбор кубкового турнира в организации соревнований по хоккею с мячом был оправдан двумя важными условиями. Во-первых, климатическими - требовалась устойчивая зимняя погода, в связи с чем, розыгрыши Кубка СССР проводились с января по первые числа марта. Во-вторых, кубковый турнир обеспечивал более массовое участие клубов из разных городов и регионов Советского Союза: в первом розыгрыше участвовало всего 48 команд, на следующий год - 111 команд, в розыгрыше 1940 года - 316 команд [26, С.248-250].

При этом, зрительский интерес у матчей по хоккею с мячом в довоенный период был сопоставим с интересом к футболу, который довольно быстро завоевал значение самого популярного вида спорта в XX веке. На довоенных финалах розыгрышей Кубка СССР по хоккею с мячом присутствовало от 20 до 40 тысяч зрителей [26, С.249251], [10, T.2, С.360-363].

О значимости хоккея с мячом в общественной жиз- ни страны говорит и тот факт, что в феврале 1942 года, когда еще продолжалась битва за Москву, было принято решение провести розыгрыш кубка Москвы по хоккею с мячом среди мужских, женских и юношеских команд [7]. Результаты матчей и ход турнира довольно подробно публиковались в газете «Красный спорт» [8], не прекращавший выходить в военные годы. В тяжелый для страны период - первой военной зимы 1941/1942 годов, хоккей с мячом рассматривался не только как один из способов отвлечения от военной повседневности, но и как средство для политической пропаганды стойкости советского человека в условиях военного времени.

Подводя итоги, следует сказать, что изначально хоккей с мячом появился в России в последние годы XIX века как «английская забава» с целью развития спортивных игр в целом. За довольно короткий период хоккей становится одним из самых популярных видов спорта в зимний период. В хоккей с мячом начинают играть повсеместно по всей стране, где имеются необходимые климатические условия зимой. На примере организации турниров по хоккею с мячом был опробован новый принцип определения сильнейшего в чемпионатах страны в командных видах спорта, когда вместо сборных городов в турнирах стали принимать участия отдельные спортивные клубы (наиболее полно этот принцип был реализован уже в футбольных турнирах). Собственная трактовка правил придала уникальный характер этому виду спорта, превращая хоккей с мячом в культурное явление первой половины XX века, которое не могло остаться без внимания со стороны государства, что особенно проявилось в первые годы Великой Отечественной войны, когда проведению московского городского турнира по хоккею с мячом придавалось общенациональное значение.

\section{ЛИТЕРАТУРА}

1. Постановление СНК СССР от 16.03.1940 №350 «0б утверждении Положения о Всесоюзном Комитете по Делам Физической Культуры и Спорта при СНК Союза ССР» // «Собрание постановлений СССР, 1940, №7, ст.209.

2. Техника хоккея: удар // Спартак. - 1926. - №5. - С.5.

3. Снаряжение хоккеиста. // Спартак. - 1926. - №47. - С.4.

4. Хоккей-бэнди и канадский хоккей // Физкультура и спорт. . - 1928. - №1. - С.3.

5. Хоккей. Всесоюзные междуведомственные соревнования // Красный спорт, 1935 - 10 марта.

6. Итоги первенства СССР по хоккею // Красный спорт, 1936 - 5 марта.

7. Хоккей. Началась борьба за Кубок Москвы // Красный спорт. 1942. - 10 февраля.

8. Х Хоккей. Финал Кубка столицы. // Красный спорт. 1942. - 3 марта.

9. Антуфьев В.Ф. Под стягом «Водника»: летопись хоккейного клуба / Виктор Антуфьев. Архангельск: 000 «Наш Север», 2004. - 467 с., ил.

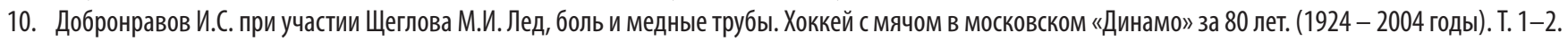
М.: Книжный клуб, 2005. - Т.1, 565 с., ил. - Т.2, 544 с., ил.

11. Зиганшин 0.3. История развития хоккея с мячом. - Хабаровск: ДВГАФК, $2006-106$ с.

12. Курош А. «Уральский трубник»: Взгляд сквозь время / Алексей Курош. - Первоуральск, 2017. - 464 с.

13. Морозов И., Дуничкин С., Пликин В. Русский хоккей в Дзержинске. - Нижний Новгород, 2016. - 304 с.

14. Москва футбольная. Люди. События. Факты: Справочник / Автор-составитель А.В. Савин. - М.: Терра-Спорт, 2000. - 560 с., ил. 
15. Муравьев С. Бэнди или Хокэй зимой и летом. Новая английская игра. С 10 рисунками. - С.-Пб.: издание книжного магазина «Труд и забава», 1906. - 16 с.

16. Осипов В.И. Хоккей с мячом: сборная СССР. - М.: Физкультура и спорт, 1984. - 142 с., ил.

17. Осипов В.И. Хоккей с мячом: справочник к XVI чемпионату мира. - М.: Советский спорт, 1989. - 136 с.

18. Отечественный хоккей с мячом. Высший и первый эшелон: 1964/1965 - 1974/1975. Справочник / Авт.-сост. В.И.Соснин. - Жуковский: «Печатный салон», ИП Зубрицкая Э.В., 2018. - 152 с., ил.

19. П. Пфейффер. Хоккей обыкновенный и на льду. Пер.с нем. Равич. - С.-Пб., М.: издательство М.П. Петрова, 1915.

20. Русский хоккей. Грации. «Рекорд»: история женского хоккея и команды «Рекорд» (1915 - 2016 гг.) / редкол.: И.А. Верхозин, М.А.Климов. - Иркутск: Издательский дом «Автомаркет», 2017. - 400 c.

21. Феномен российской интеллигенции конца XIX - начала XX века. Монография / Кол.авт. Рябов В.В., Токарева Е.А., Орчакова Л.Г., и др.; науч.ред. В.В. Кириллов. - М.: Издательство «0нтоПринт», 2020. - 204 с.

22. Фролов В.В. На ледяных полях: обзор важнейших хоккейных соревнований в сезонах 1954/1955 и 1955/1956 годов. - М.: Гос. изд-во «Физкультура и Спорт». 1957. - $190 \mathrm{C}$.

23. Хоккей в СССР. Справочник. / Авт.-сост. А.С. Перрель. М.: Гос. изд-во «Физкультура и спорт». 1955. - 183 с.

24. Хоккей с мячом. Хоккей на траве. Справочник / Авт.-сост. А.В.Комаров. - М.: «Физкультура и спорт», 1979. - 208 с.

25. Хоккей с мячом: Энциклопедия / Сост. Соснин В. И., Щеглов М. И., Юрин В.Л. — М.: Новые технологии, 2009. — 808 с.: ил.

26. Щеглов М. «Зоркий» (Красногорск): Хроника сорокалетия. - М.: Новое дело, 2003. - 752 с.: ил. (+вкл.).

27. Анохина А.Б. Развитие физической культуры и спорта в Ульяновской области в 1945 - 1991 гг. : Дис. ... канд. истор. наук. Ульяновск, 2019. - 288 с.

28. Каркавцева И.А. Физиологическое обоснование адекватного распределения физической нагрузки различной метаболической мощности в годичном цикле подготовки квалифицированных хоккеисток: Автореф. дис. ... канд. биолог. наук. Архангельск, 2007. - 19 с.

29. Фатеева 0.А. Методика эффективности техники бега на коньках хоккеистов с мячом 12-15 лет: Автореф. дис. ... канд. педагог. наук. Хабаровск, 2007. $24 \mathrm{c}$.

30. Ходкевич В.А. Методика подготовки вратарей в хоккее с мячом на этапе начальной специализации: Автореф. дис. .... канд. педагог. наук. Хабаровск, 2011. $-25 \mathrm{c}$.

31. Ice Hockey, by major B.V.Patton. London: George Routledge \& Sons Ltd., 1936. - 176 p.

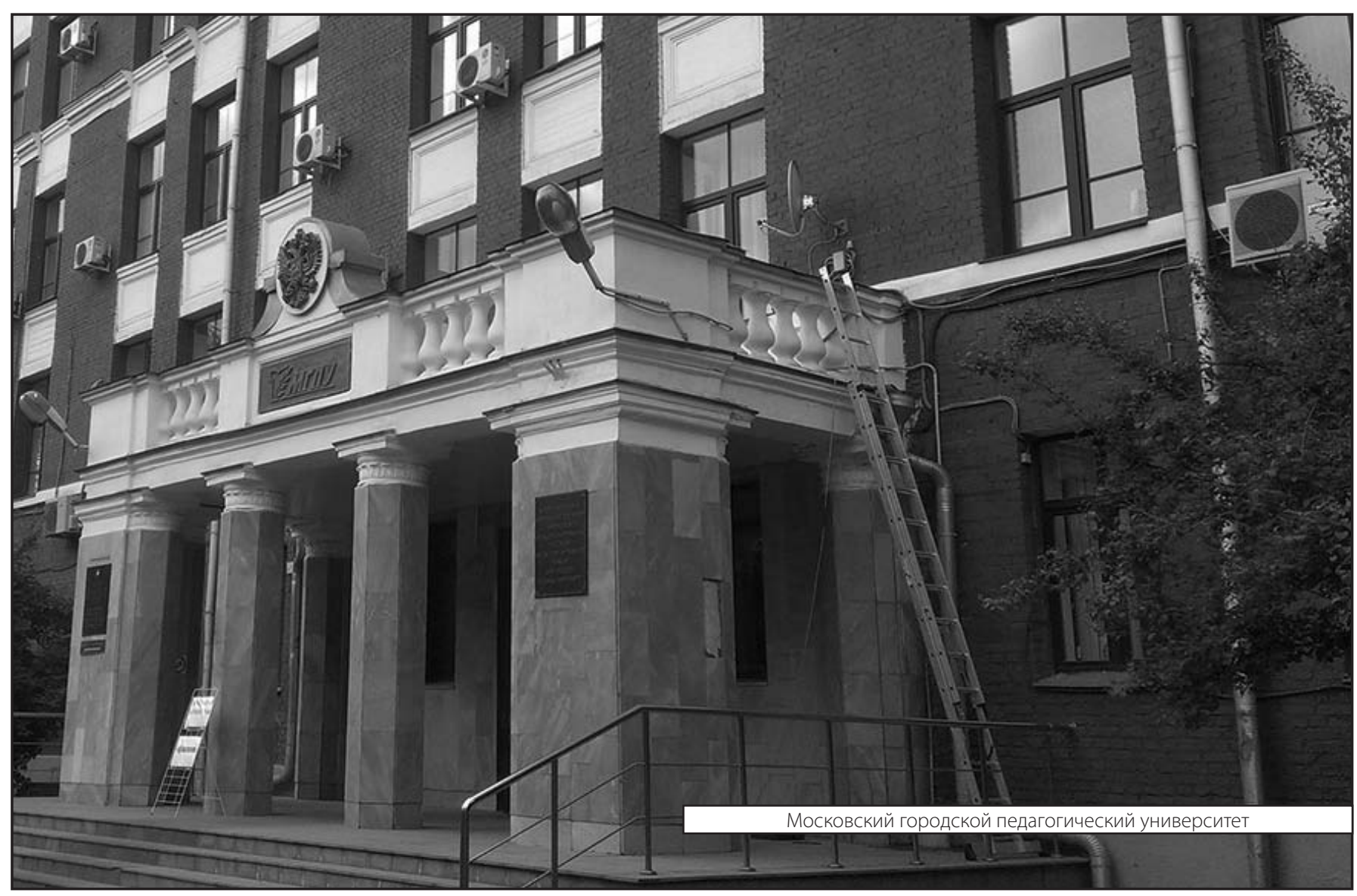

